\title{
A COMPARATIVE ANALYSIS OF NUMBER PORTABILITY ROUTING SCHEMES
}

\author{
Suman Deswal, Anita Singhrova \\ Computer Science and Engg. Deptt., DCRUST, Murthal.
}

\begin{abstract}
To reap the benefits of liberalized telecom market, the implementation of number portability (NP) is utmost important. NP allows end user to retain their telephone number in case of change of geographical location or service type or service provider. This paper describes the various number portability routing schemes namely, All Call Query, Query on Release, Call Dropback and Onward routing. The comparative analysis between these routing schemes on various parameters is presented here. The issues pertaining to NP have also been described.
\end{abstract}

\section{KEYWORDS}

Number portability, Query on Release, All Call Query, Call Dropback, Onward routing.

\section{INTRODUCTION}

Number portability (NP) is a circuit-switch telecommunications network feature that enables end users to retain their telephone numbers when changing service providers, service types and geographical locations. Earlier, in absence of NP, customers had to change their numbers with change of service provider, service types or geographic locations. The paradigm shift to a "consumer-centric" number ownership model, rather than the "carrier-centric" number ownership model has resulted in number portability. Number Portability is beneficial to the user as it does not require the need of informing others of number change and it has increased the competition in the telecommunication market which has resulted in lower prices and greater customer satisfaction. Further, once implemented by all the wireline and wireless service providers, it will significantly reduce the switching cost for customers.

\subsection{Types of Number Portability}

Three types of number portability have been identified.

a) Service provider portability: It is the ability of users of telecommunications services to retain, at the same location, existing telecommunications numbers without impairment of quality, reliability, or convenience when switching from one telecommunications carrier to another.

b) Location Portability: It is the ability of users of telecommunications services to retain existing directory numbers without impairment of quality, reliability, or convenience when moving from one physical location to another. 
c) Service Portability: It is the ability of users of telecommunications services to retain existing directory numbers without impairment of quality, reliability, or convenience when switching from one service to another service provided by the same carrier. For example from mobile to fixed and from fixed to mobile.

Since there are multiple service providers now a days at the same geographical location, this paper discusses service provider portability in detail.

\subsection{Call routing process:}

The call routing process is dependent upon the service provider of both, the host and the destination nodes. Before discussing the call routing process let us define some terms used in the paper:

- Serving Network: The serving network is the network that served the number before it was ported to the new serving network.

- Recipient Network: A recipient network is a network that a subscriber's number is ported to when the subscriber switches the service provider.

- Donor Network: It is a network that user subscribed to initially. Since a subscriber can switch service provider any number of times, the old service provider is not necessarily the same as the donor network.

There can be two different cases for call routing:

(i) The host and destination are in the same service provider network:

Since host and destination are in same service provider network so the call is directly routed by the serving exchange in the serving network as shown in Figure 1..

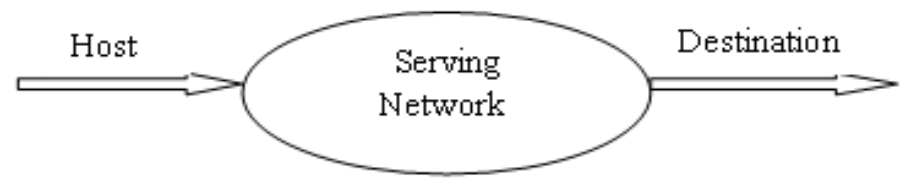

Figure 1. Call routing process in same network

(ii) The host and destination are in the different service provider network:

When host and destination nodes are in different networks then (1) host makes a call to the serving network and then (2) the serving network provides information to route to a database(within the recipient network or which is accessed by the recipient network) which provides the subsequent routing information to be used by recipient exchange, (3) to connect to customer's interface as shown in Figure 2.

The remainder of this paper is structured as follows: Section II summarizes work related to number portability. Section III discusses various service provider number portability schemes. Comparative analysis for various number portability routing schemes is presented in section IV. Main issues related to number portability are presented in section $\mathrm{V}$ followed by conclusion in section VI. 


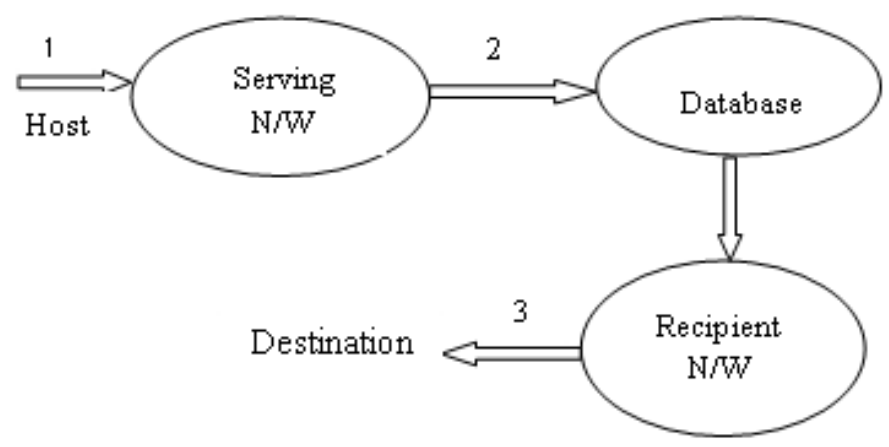

Figure 2. Call routing process in different networks

\section{LITERATURE SURVEY}

In [1] authors describe the impact of Mobile number portability (MNP) on mobile telephony retail prices using international time-series cross-section data. The results indicate that average prices are reduced when the switching process is rapid. In [2] the author discusses that Mobile customers want to switch operators in return for better quality of service and/or call rates, are benefited by the MNP facility as they do not incur costs to update their networks about a number change. The importance of having a dynamic market and as many willing operators as possible is presented in [3]. This will help regulators to work with a group of determined individuals ideally pushing for the facility. In [4] the author argues that the introduction of MNP generates various competitive effects that are of potential interest to regulatory authorities. It provides an analytical framework for studying the economic costs associated with a reduction in tariff transparency that may result if the prefix of a mobile telephone number no longer indicates its network assignment. The introduction of mobile number portability divides the mobile operators into two groups as the new mobile operators are benefitted and the old ones loose. Effects on mobile customers are also ambiguous [4]. The necessity of mobile number portability into the developing telecom markets of South Asia has been explored in [5]. In [6] the authors study that MNP has a positive effect on customers because in order to retain customers, the service providers give more beneficial schemes to customers. The only thing that needs attention is the time and cost for switching.

\section{TYPES OF CALL ROUTING SCHEMES}

When the destination node moves to a new service provider network, the call can be routed using different ways. The database of ported number is NPDB (Number Portability Database ). The NPDB provides the LNP (Local Number Portability) association between the called party and the carrier RN (Routing Number), identifying the switch to which the call should be routed. NPDB is maintained using either centralized or distributed approach $[7,8]$.

\section{(i) Centralized approach}

In centralized approach, there is a centralized database. All service providers have a well defined interaction with the centralized database administrator for processing the request for porting a number. There is no direct interface between two service providers. Any porting request is processed by the administrator, which after taking clearance from the current service provider broadcasts the porting information to all the service providers.

\section{(ii) Distributed Approach}


In distributed approach, there is a direct interfacing between two service providers. One service provider can have interfacing with many other service providers. Therefore, this has the disadvantage of becoming complex as the number of service providers in a country increases.

The different schemes for routing of ported numbers are explained below:

\section{a. All Call query (ACQ)}

Upon receiving a call, the originating network sends a query to a centrally administered NPDB. It returns a Routing Number (RN) associated with the dialled number. The RN number is used by the originating network to route the call to the recipient network. This is also called direct routing [8]. The flow of call routing is shown in Figure. 3.

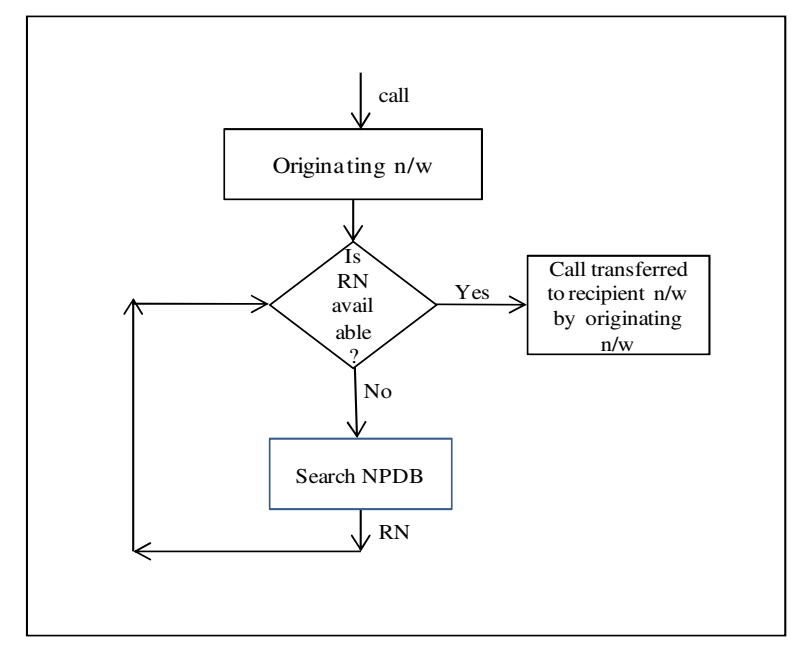

Figure 3. Flow chart for ACQ

\section{b. Query on release (QoR)}

The originating network sends the call to the donor network. It then detects that the called number has been ported out to another network. It thereafter releases the call with a special indication telling that called number is ported out. The originating network then sends a query to its own Number Portability Database (NPDB). The NPDB returns the routing number (RN) associated with the dialled number. The originating number then routes the call to the new servicing network[8]. The flow of call routing is shown in Figure 4.

\section{c. Onward Routing}

The originating network sends the call to the donor network. The donor network checks the Number Portability Database (NPDB) and finds that the number has moved out of donor switch. The donor network makes a query to NPDB. NPDB returns the routing number associated with the dialled number. The donor network uses the routing number to forward the call to new network[8]. This is also called call forwarding and is shown in Figure 5. 
International Journal of Computer Networks \& Communications (IJCNC) Vol.6, No.2, March 2014

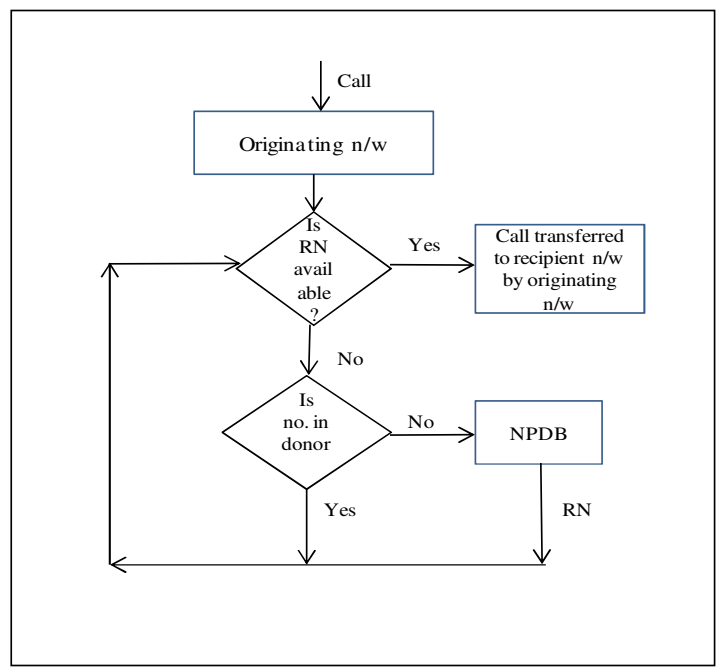

Figure 4. Flow chart for QoR

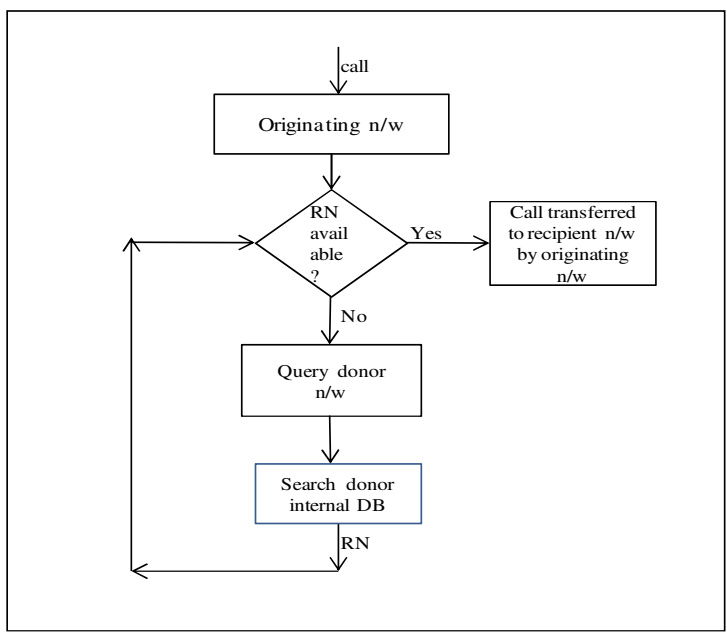

Figure 5. Flow chart for Onward Routing

\section{d. Call Dropback}

The originating network sends the call to the donor network. The donor network checks its internal database. On non availability of the number, the donor network makes a query to NPDB and finds the routing number associated with the dialled number. It returns the routing number to the originating network. The originating network then routes the call to the new servicing network using the routing number as shown in Figure 6 [9]. 


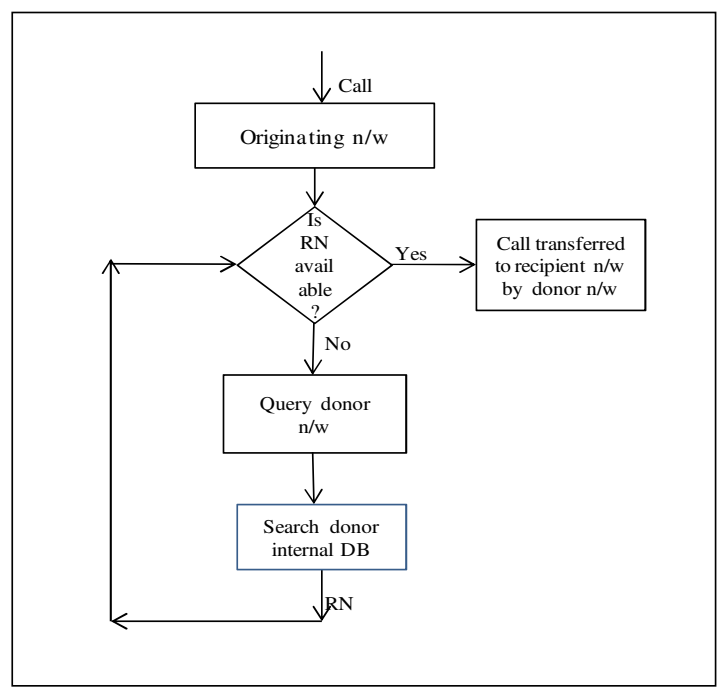

Figure 6. Flow chart for Call Dropback

\section{ISSUES RELATED TO NUMBER PORTABILITY}

\subsection{Porting time}

Porting time is the time needed to port a number from one subscriber to another. It should be as minimum as possible because if the porting time increases there is a tendency to refrain from porting.

\subsection{Cost}

Setup cost: It leads to increase in cost for the service providers which includes the cost of additional infrastructure, both hardware and software, required to enable appropriate rerouting of calls made to subscribers who have switched networks.

Operational cost: The operators also need to invest in the setting up of Number Portability database either centrally administered or operator specific. This includes the initial cost of development and an ongoing cost of operation and maintenance.

Administrative cost: The administrative process of porting a number involves cost for the recipient network operator, donor network operator and the operator of a number database. All these can pass on the administrative cost to the user requesting the port. The switching of identity also causes significant costs to users as mobile number is used as an identifier for many applications on mobile [10]. These prices should be regulated to ensure that the subscribers are not overcharged.

\subsection{Data transmission}

For ported number, the data transmission in case of SMS and MMS poses greater challenge as both the sender and the receiver may be unaware of the loss of data. Therefore, messaging requires urgent attention when the number has been ported to a new service provider. 


\section{COMPARISON OF ROUTING SCHEMES}

Table 1. Comparative Analysis of call routing Schemes

\begin{tabular}{|c|c|c|c|c|}
\hline Parameters & ACQ & QoR & Call Dropback & Onward \\
\hline $\begin{array}{l}\text { NPDB } \\
\text { searched }\end{array}$ & $\begin{array}{ll}\text { originating } & n / w \\
\text { searches } \\
\text { centralized } \\
\text { NPDB once }\end{array}$ & $\begin{array}{l}\text { originating } \mathrm{n} / \mathrm{w} \\
\text { searches } \\
\text { centralized } \\
\text { NPDB once }\end{array}$ & $\begin{array}{lr}\text { Donor } & \mathrm{n} / \mathrm{w} \\
\text { searches } & \text { its } \\
\text { internal database } \\
\text { once }\end{array}$ & $\begin{array}{lr}\text { Donor } & \mathrm{n} / \mathrm{w} \\
\text { searches } & \text { its } \\
\text { internal } & \text { database } \\
\text { once } & \end{array}$ \\
\hline $\begin{array}{l}\text { Search } \\
\text { Complexity for } \\
\text { routing } \\
\text { number(RN) }\end{array}$ & $\begin{array}{l}\text { Less (makes a } \\
\text { direct query to } \\
\text { NPDB for RN) }\end{array}$ & $\begin{array}{l}\text { More (makes a } \\
\text { query to donor } \\
\mathrm{n} / \mathrm{w} \text { prior to } \\
\text { NPDB for RN) }\end{array}$ & $\begin{array}{l}\text { Less(donor } \mathrm{n} / \mathrm{w} \\
\text { makes a query } \\
\text { to its internal } \\
\text { database) }\end{array}$ & $\begin{array}{l}\text { less(donor } \mathrm{n} / \mathrm{w} \\
\text { makes a query to } \\
\text { its internal } \\
\text { database) }\end{array}$ \\
\hline $\begin{array}{l}\text { Efficiency in } \\
\text { terms of } \\
\text { network } \\
\text { resources used }\end{array}$ & $\begin{array}{l}\text { High(does not } \\
\text { involve donor } \\
\mathrm{n} / \mathrm{w} \text { to route a } \\
\text { call to recipient } \\
\mathrm{n} / \mathrm{w} \text { ) }\end{array}$ & $\begin{array}{l}\text { Less(involves } \\
\text { both donor } \mathrm{n} / \mathrm{w} \\
\& \text { centralized } \\
\text { NPDB) }\end{array}$ & $\begin{array}{l}\text { Less(donor } \mathrm{n} / \mathrm{w} \\
\text { sends the } \mathrm{RN} \text { to } \\
\text { originating } \mathrm{n} / \mathrm{w} \\
\text { which then } \\
\text { forwards the call } \\
\text { to recipient } \mathrm{n} / \mathrm{w} \text { ) }\end{array}$ & $\begin{array}{l}\text { Moderate (donor } \\
\mathrm{n} / \mathrm{w} \text { forwards the } \\
\text { call to recipient } \\
\mathrm{n} / \mathrm{w})\end{array}$ \\
\hline $\begin{array}{l}\text { Dedicated } \\
\text { signalled } \\
\text { circuit } \mathrm{b} / \mathrm{w} \\
\text { originating } \mathrm{n} / \mathrm{w} \\
\text { and donor } \mathrm{n} / \mathrm{w}\end{array}$ & $\begin{array}{lll}\text { No( } & \text { no } & \text { donor } \\
\mathrm{n} / \mathrm{w}) & & \\
\end{array}$ & $\begin{array}{l}\text { Yes(donor } n / w \\
\text { replies back to } \\
\text { the originating } \\
n / w)\end{array}$ & $\begin{array}{l}\text { Yes(donor } n / w \\
\text { replies back to } \\
\text { the originating } \\
n / w)\end{array}$ & $\begin{array}{l}\text { No (call is } \\
\text { forwarded } \\
\text { directly } \\
\text { recipient } \mathrm{n} / \mathrm{w} \text { by } \\
\text { the donor } \mathrm{n} / \mathrm{w})\end{array}$ \\
\hline $\begin{array}{ll}\text { Call routing } \\
\text { Cost }\end{array}$ & Low & High & High & Moderate \\
\hline $\begin{array}{l}\text { Acceptance of } \\
\text { government } \\
\text { regulations by } \\
\text { Service } \\
\text { provider }\end{array}$ & Yes & Yes & Yes & Yes \\
\hline $\begin{array}{l}\text { Maintenance } \\
\text { of portability } \\
\text { information by } \\
\text { donor } \mathrm{n} / \mathrm{w}\end{array}$ & Not required & Not required & Required & Required \\
\hline $\begin{array}{l}\text { Increase in } \\
\text { Network } \\
\text { traffic per call }\end{array}$ & Low & High & High & Moderate \\
\hline $\begin{array}{l}\text { Approach for } \\
\text { Database } \\
\text { maintenance }\end{array}$ & Centralized & Centralized & Distributed & Distributed \\
\hline
\end{tabular}


Table 1 shows the comparison of different call routing schemes. By virtue of their implementations various routing schemes exhibit different behaviour for different parameters. Routing of a call is done directly from originating $n / w$ to the correct recipient $n / w$ in ACQ by deriving RN from NPDB whereas all other routing schemes require donor $\mathrm{n} / \mathrm{w}$ to determine $\mathrm{RN}$. This involvement of donor $\mathrm{n} / \mathrm{w}$ in QoR, Call Dropback and Onward routing increases search complexity, cost and reduces efficiency. Dedicated signalled circuit is required between originating $n / w$ and donor $n / w$ in QoR and Call Dropback as call is made by originating $n / w$ after receiving RN. To and fro movement of RN increases network traffic per call in case of QoR and Call Dropback.

ACQ is best suited in terms of cost whereas Onward routing is the simplest routing method to implement. The costs and complexity associated with the other two methods lie between those of all call query and onward routing.

\section{CONCLUSION}

The increased usage of mobile phones by the users has led to the implementation of mobile number portability. This will not only allow the users to change the location/service provider without changing their number but would also enforce the healthy competition amongst the service providers. As the service providers would be desperate to retain their high revenue customers, they would reduce overall cost, improve QoS and provide add on services in addition.

This paper discusses the various routing schemes in detail. Thorough comparison carried out on various parameters such as cost, complexity, search time etc. on all the routing schemes revealed that ACQ is best suited in terms of cost Whereas Onward routing is the simplest routing method to implement. The costs and complexity associated with the other two methods lie between those of all call query and onward routing.

\section{REFERENCES}

[1] Sean Lyons,(2010) "Measuring the effects of mobile number portability on service prices" Journal of Telecommunications Management, Vol. 2, No.4, pp. 357 - 368.

[2] Buehler, S., Dewenter, R. and Haucap, J, (2006) "Mobile Number Portability in Europe" Telecommunications Policy, Vol. 30, No. 7, pp. 385-399.

[3] Gans, J.S. and S.P. King (2000), "Mobile network competition, customer ignorance and fixed-tomobile call prices, Information Economics and Policy”, Elsevier, Vol. 12, No.4, pp. 301-327.

[4] Stefan Buehler, Justus Haucap (2004), "Mobile Number Portability", Journal of Industry, Competition, and Trade, Vol. 4, No. 3, pp. 223-238.

[5] Tahani Iqbal (2011), "Mobile Number Portability in South Asia", Proceedings of the 5th ACORNREDECOM Conference. Lima.

[6] Sanjeet Singh, Gagan Deep Sharma, Gurbhej Singh (2011), "Customer Perception and Expectation of Mobile Number Portability", e-Journal on Telecommunications and Regulated Industries, doi:10.2139/ssrn.1852019.

[7] Atiya Faiz Khan (2010), "Mobile Number Portability: Challenges and solutions", Journal of Emerging Trends in Computing and Information Sciences, Vol. 2.

[8] Sánchez, B. U., and Asimakopoulos, G. (2012)," Regulation and competition in the European mobile communications industry: An examination of the implementation of mobile number portability" telecommunication policy, Elsevier, Vol. 36, No. 3, pp. 187-196. 
[9] A.Gallant (2000), “The Number Portability Supplement to ITU-T Recommendation E.164”, <draftietf-enum-e164s2-np-00.txt>.

[10] Cho, D., Ferreira, P., \& Telang, R. (2012), “ The impact of Mobile Number Portability on Switching cost and Pricing Strategy". Paper presented at the 40th Research Conference on Communication, Information and Internet Policy, Arlington, VA.

Suman Deswal, Assistant professor, Dept. of Computer Science and Engg., DCR University of Science and Technology, Sonepat, India. Suman Deswal has completed her M.Tech (Computer Science and engineering) from Kurukshetra University, Kurukshetra, India and B.Tech (Computer Science \& Engineering) from DCRUST, Murthal, India (erstwhile CRSCE Murthal) in 2009 and 1998 respectively. Currently, She is enrolled for Ph.D. and working on mobility in Heterogeneous Networks. She has 13 years of teaching experience. Her research areas include Mobile computing and heterogeneous networks. She has contributed in various research papers in various National and International journals.

Anita Singhrova, Professor, Dept. of Computer Science and Engg., DCR University of Science and Technology, Sonepat, India. She holds a Ph.D degree from GGS Indraprastha University, Delhi, India. She has completed M.E (Computer Science \& Engg.) from Punjab Engineering College, Chandigarh, India and B.Tech(Computer Science) from T.I.T\&S, Bhiwani, India 2006 and 1993 respectively. She has also been certified as Java Programmer by Sun Microsystems. She possesses seventeen years of teaching experience

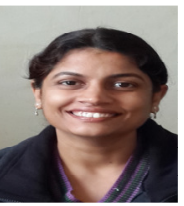
and is presently working as Professor in the department of Computer Science and Engg. at DCR University of Science and Technology, Sonepat, India. Her research interests include network security, Mobile computing and heterogeneous networks. She has contributed in various research papers and articles in various National and International journals and conferences. 